Article

\title{
Performance Evaluation of a Potential Component of an Early Flood Warning System-A Case Study of the 2012 Flood, Lower Niger River Basin, Nigeria
}

\author{
Dorcas Idowu and Wendy Zhou * \\ Department of Geology and Geological Engineering, Colorado School of Mines, Golden, CO 80401, USA \\ * Correspondence: wzhou@mines.edu; Tel.: +1-303-384-2181
}

Received: 8 July 2019; Accepted: 15 August 2019; Published: 21 August 2019

\begin{abstract}
Floods frequently occur in Nigeria. The catastrophic 2012 flood in Nigeria claimed 363 lives and affected about seven million people. A total loss of about 2.29 trillion Naira (7.2 billion US Dollars) was estimated. The effect of flooding in the country has been devastating because of sparse to no flood monitoring, and a lack of an effective early flood warning system in the country. Here, we evaluated the efficacy of using the Gravity Recovery and Climate Experiment (GRACE) terrestrial water storage anomaly (TWSA) to evaluate the hydrological conditions of the Lower Niger River Basin (LNRB) in Nigeria in terms of precipitation and antecedent terrestrial water storage prior to the 2012 flood event. Furthermore, we accessed the potential of the GRACE-based flood potential index (FPI) at correctly predicting previous floods, especially the devastating 2012 flood event. For validation, we compared the GRACE terrestrial water storage capacity (TWSC) quantitatively and qualitatively to the water budget of TWSC and Dartmouth Flood Observatory (DFO) respectively. Furthermore, we derived a water budget-based FPI using Reager's methodology and compared it to the GRACE-derived FPI quantitatively. Generally, the GRACE TWSC estimates showed seasonal consistency with the water budget TWSC estimates with a correlation coefficient of 0.8 . The comparison between the GRACE-derived FPI and water budget-derived FPI gave a correlation coefficient of 0.9 and also agreed well with the flood reported by the DFO. Also, the FPI showed a marked increase with precipitation which implies that rainfall is the main cause of flooding in the study area. Additionally, the computed GRACE-based storage deficit revealed that there was a decrease in water storage prior to the flooding month while the FPI increased. Hence, the GRACE-based FPI and storage deficit when supplemented with water budget-based FPI could suggest a potential for flood prediction and water storage monitoring respectively.
\end{abstract}

Keywords: flood; FPI; GRACE; terrestrial water storage anomaly; storage deficit

\section{Introduction}

Flooding is a major disaster in Nigeria, especially along the Niger and Benue Rivers. In Nigeria, it occurs in three main forms: Coastal floods which occur in mangrove and delta coastlines; river floods which occur on the flood plains of large rivers; and flash floods which are short-lived events developing in less than 6 hours from rainfall to the onset of flooding [1,2].

In 2012, heavy rainfall during the wet season combined with the release of water from Ladgo Dam in Cameroon led to a catastrophic flooding event that affected 30 states out of the 36 states of the country. The flooding which was described by the Nigeria National Emergency Management Agency as the worst in 40 years, claiming 363 lives, affecting about 7 million people, while a total loss of about 2.29 trillion Naira (7.2 billion US Dollars) was estimated. 
The developed countries are still affected by disasters resulting from floods but have flood alert systems (such as the European Flood Alert System [3] and the US National Weather Service Automated Flood Warning System [4]) in place which are effective in providing a monitoring and warnings service. A significant portion of the economic losses caused by floods occur in developing countries where ground flood monitoring and management programs are still inefficient, and the costs of building water control infrastructure such as dams, weirs, embankments and gauging stations can be prohibitive [5]. Also, ground-based methods used to monitor floods are based on hydro-meteorological data such as discharge and precipitation which are time-consuming in terms of collection and processing and are also affected by varying weather conditions. Furthermore, worthy of mentioning is the recent problem of security in Nigeria which may also inhibit the installation of these systems.

Over the years, there have been novel advances on remote sensing for forecasting and monitoring hydrological extremes such as floods and droughts. Victor [6] studied the use of satellite data for flood delineation, monitoring and prediction. Nasreddine et al. [7] developed a new flood forecasting approach for flood disaster management in poorly or totally ungauged watersheds using precipitation measurements. Sheffield et al. [8] and Zhang et al. [9] applied satellite data to monitoring and forecasting drought.

In recent decades, satellite data availability has improved dramatically and to complement the ground-based observations, flood monitoring has increasingly relied on the products obtained with space-borne sensors such as National Aeronautics and Space Administration (NASA) advanced microwave scanning radiometer for EOS (AMSR-E) [10] and moderate resolution imaging spectroradiometer (MODIS) [11]. Zhan et al. [12] explored the marginal benefit of incorporating space-borne soil moisture measurements into a hydrologic model for improved streamflow and flood prediction. They incorporated the surface soil moisture data from the AMSR-E into the Noah land surface model within the land information system (LIS). Their findings suggested the potential for improving flood forecasting through the assimilation of remotely sensed soil moisture data into a hydrologic model. Among the remote sensing products that have been used for flood monitoring, prediction and forecasting, data from the Gravity Recovery and Climate Experiment (GRACE) $[13,14]$ are unique in that the changes in the amount of terrestrial water can be directly measured.

The GRACE satellite mission was launched in March 2002. It presents a means to observe monthly variations in total/terrestrial water storage within large $\left(>200,000 \mathrm{~km}^{2}\right)$ river basins based on measurements of changes in Earth's gravity field [15]. These changes result when the amount of water stored in a region increases or decreases, which produces a ripple effect leading to the gravity signal in that region increasing or decreasing proportionately. The predictive ability of a GRACE-based flood potential has been compared to flood prediction models that use traditional input data sources such as river heights, snow amounts and the wetness of surface soils [16]. The method of GRACE storage deficit estimates could be used in combination with traditional remote sensing methods of precipitation forecasting to help assess the likelihood for flooding [16]. However, their reliability and efficacy for applications in developing countries need to be assessed due to the sparse availability of ground measurement data.

Reager and Famiglietti [17] proposed the flood potential index (FPI) to estimate flood risks worldwide based on GRACE terrestrial water storage anomaly (TWSA) and precipitation records. A qualitative comparison of FPI with a record of observed floods from the Dartmouth Flood Observatory (DFO) data set suggested that the proposed FPI product is useful for flood risk assessment in most regions [17].

Molodtsova et al. [18] tested the FPI in the United States where a dense network of flood gauges has been established, and reported that, potentially, a greater use of this method is in developing countries, where due to inadequate monitoring capability, floods tend to cause significant damage and the most loss of life. Additionally, they reported that floods in African countries, as found through the DFO database, are mainly caused by heavy rainfall events, for which the FPI seems to perform well in predicting flood potential. 
Molodtsova et al. [18] went further to study the Juba-Shabelle River Basin, a 783,000 km² watershed shared between Somalia and Ethiopia, and found an increasing FPI was in the watershed one month prior to the flood and during the month of the flood, where both predictions agreed well with the actual flood extent area reported by the DFO. Based on their analysis, they inferred that developing countries with sparse or inadequate flood monitoring networks are potential beneficiaries of this approach.

Sun et al. [19] evaluated the GRACE FPI over the Yangtze River Basin (YRB) in China and suggested that estimates of terrestrial water storage based on GRACE, measured as FPI, are critical for understanding and predicting flooding. Thus, they concluded that GRACE data can be effectively used for monitoring and examining large floods in the YRB and elsewhere.

For our study, we chose the Lower Niger River Basin, Nigeria (Figure 1) as our area of interest, and the flooding event in 2012 as our case study (Table 1) because it was the worst in 40 years. We investigated the capacity of the GRACE TWSA (terrestrial water storage capacity, TWSC) in accurately capturing and predicting the 2012 flood event, and other flood years within the basin. We also evaluated the hydrological condition of the basin in terms of the available storage and predisposition to flooding. The GRACE-derived FPI was validated using the DFO report and compared to a water budget-derived FPI.



Figure 1. Map showing the boundaries of the Lower Niger River Basin in Nigeria with the states prone to Flooding (Nigeria National Emergency Management Agency). 
Table 1. Statistics for the most devastating flood disasters in 2012 (compiled by authors based on [20]).

\begin{tabular}{cccccc}
\hline Country & Date & Death Toll & $\begin{array}{c}\text { Number of } \\
\text { People Affected }\end{array}$ & $\begin{array}{c}\text { Number of } \\
\text { People Displaced }\end{array}$ & Cause(s) \\
\hline Pakistan & September & 455 & $>5,000,000$ & 350,000 & Cost of Damage \\
Nigeria & July-October & 363 & $7,000,000$ & $2,100,000$ & Heavy monsoon rains \\
North Korea & July-September & 330 & N/A & 241,547 & Torrential rains and tropical storm Khanun \\
Russia & July & 171 & 30,000 & 13,000 & Heavy rainfall \\
Philippines & August & 95 & $1,230,000$ & 15,134 & Norillion \\
China & July & 79 & $>1,600,000$ & 56,933 & Torrential rains \\
India & August & 35 & $>12,000$ & N/A & Heavy rainfall \\
Nepal & May & 26 & N/A & N/A & Flonsoon rainfall \\
\hline
\end{tabular}




\section{Data and Methods}

\subsection{Study Area}

The Lower Niger River Basin (LNRB) is so termed because of its location within the Niger River Basin (NRB). Located in West Africa, the NRB covers $7.5 \%$ of the continent and cuts across ten countries. With a total area of approximately 2.2 million $\mathrm{km}^{2}$ and a total length of $4100 \mathrm{~km}$, the NRB is the third-longest river in Africa. It is divided into four parts, the Upper Niger River System, the Inner Delta, the Middle Niger River System and the LNRB. The major river within the basin is the Niger River which starts in the highlands of Guinea (upstream) threading eastwards mainly through Mali, Niger and Nigeria (downstream) before entering the Gulf of Guinea to the Atlantic Ocean. Its unusual crescent shape takes it inland towards the Sahara before turning south-west to the Gulf. Along its route, the river hydrology changes from its rain-fed headwaters, it loses flow and volume as it nears the Sahara where it forms an inland delta. The inland delta is an area of high evaporation that is composed of a number of slow-moving channels. Only after the Benue River joins the river in Nigeria does it become a large river once more. The Benue River (Figure 1) which is the major tributary that feeds the Niger River Basin in Nigeria meets the Niger River (Figure 1) to form a confluence in Lokoja (Figure 2), Nigeria. Rivers Niger and Benue (Figures 1 and 2) are the two largest rivers in West Africa. The water in the Niger River is partially regulated through dams.

In September, the Benue reaches its flood level. It begins to fall in October and falls rapidly in November, continuing slowly over the next three months to reach its lowest level in March and April. Annually, these rivers experience flooding as a result of the annual heavy rainfall which coincides with the wet season in Nigeria [21] and because of poor urban planning, settlements located within the floodplains and in the proximity of the river get flooded [22] (Figure 2).

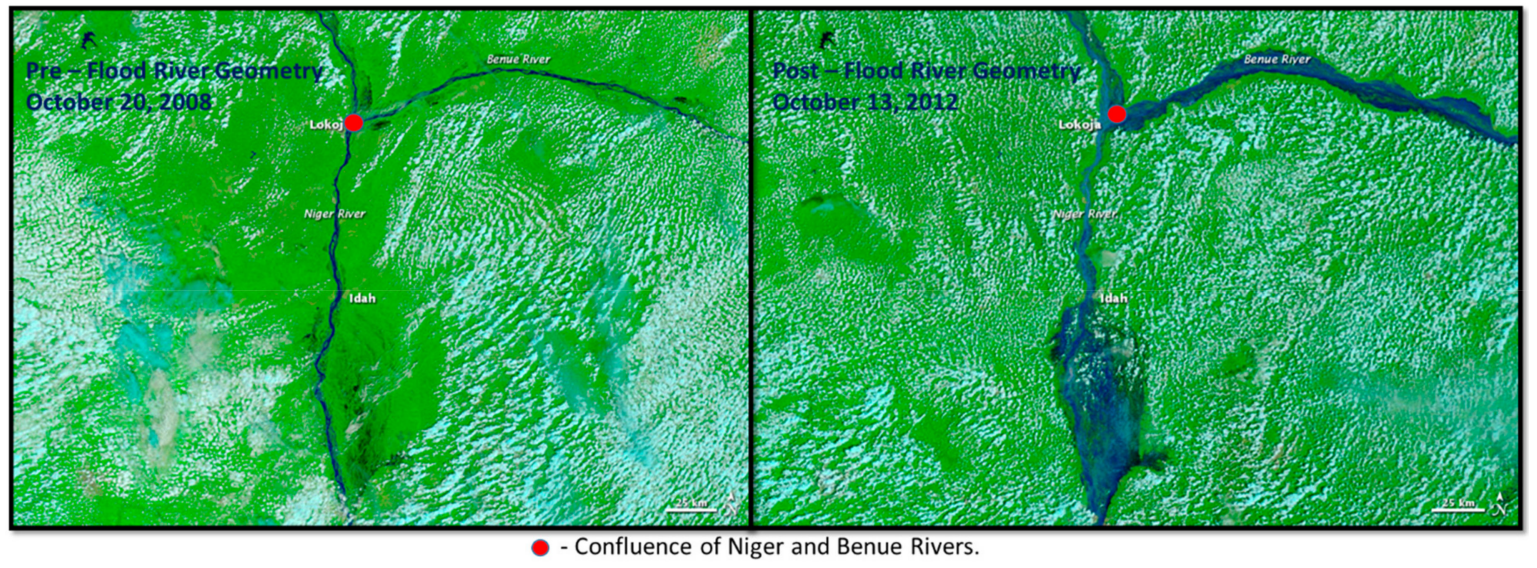

Figure 2. NASA's Terra (Moderate Resolution Imaging Spectroradiometer) satellite images showing the pre flood (normal river geometry) and post flood river geometry of the Benue River and Niger and Benue confluence point. Post - flood image was captured in 2012. (Modified after [23])

In 2012, the flooding was devastating and in spite of the increasing awareness in combating flood hazard in along the rivers, the menace had recurred. This is because past flood control strategies have not achieved the desired result due to a lack of understanding of the hydrological variables that influence the persistence of these floods. The Nigerian National Emergency Management Agency (NEMA), in 2012 listed the flood-prone states in the country. Most of these states are within the LNRB and along the Niger and Benue Rivers (Figure 1). 


\subsection{Datasets}

\subsubsection{GRACE Terrestrial Water Storage Anomaly Products}

The three official solutions (spherical harmonics solutions), the JPL (Jet Propulsion Laboratory), GFZ (GeoforschungsZentrum Potsdam) and CSR (Center for Space Research at University of Texas, Austin) of the GRACE RL05 TWSA product [24] were downloaded (http://grace.jpl.nasa.gov), from January 2004 to December 2012. The workflow in Figure 3 was applied to the datasets to derive the TWSA for the baseline of the study. The scaling factor suggested by the GRACE Tellus data portal [24] was applied to the GRACE data to account for the attenuation of small-scale surface mass variations [25]. For some years within our baseline of our study, some monthly TWSA data were missing. This is because, since early 2011, the GRACE instruments were periodically turned off due to active battery management. Those months were not considered in our study.

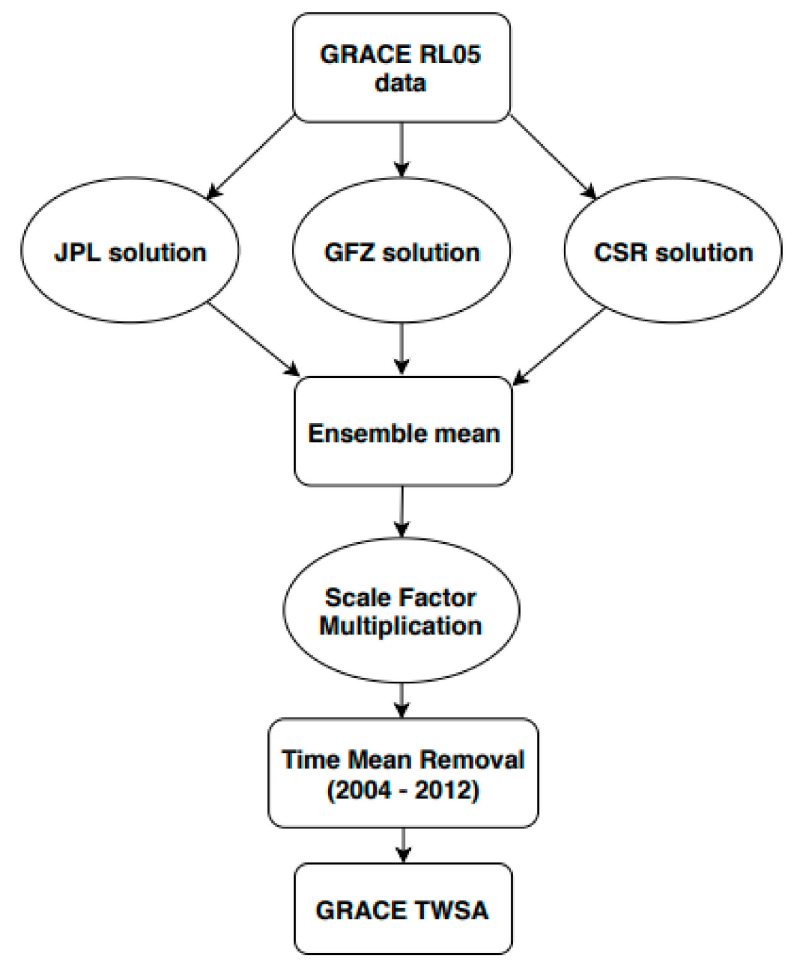

Figure 3. The basic workflow for the gravity recovery and climate experiment (GRACE) RL05 processing.

\subsubsection{Evaluation of GRACE and Water Budget Terrestrial Water Storage Change (TWSC)}

The GRACE TWSA was evaluated against the traditional water balance estimates before being used in generating the FPI. First, we calculated the TWSC from GRACE TWSA, then from the traditional water budget equation. The following water balance equation was used:

$$
\frac{d s}{d t}=P-R-E T-S M-G W
$$

where $\frac{d s}{d t}$ is the monthly change in terrestrial water storage, $P$ is monthly precipitation, $R$ is a monthly runoff, $E T$ is monthly evapotranspiration, $S M$ is soil moisture and $G W$ is groundwater.

The change was calculated for our time steps using Equation (2).

$$
d s / d t=T W S C(t)-T W S C(t-1) / t
$$

For this study, the water balance data $(P, R, E T, S M$ and $G W)$ were obtained from the eartH2Observe water cycle integrator (WCI) [26]. 


\subsubsection{Global Precipitation Climatology Centre (GPCC)}

The $1 \times 1$ GPCC precipitation data, provided by the NOAA/OAR/ESRL PSD, Boulder, Colorado, USA [27] were used for deriving the FPI. Monthly data from January 2004 to December 2012 were downloaded while the datasets corresponding to the missing datasets in GRACE TWSA were removed to create consistency in data comparison.

\subsubsection{Dartmouth Flood Observatory}

Since ground flood monitoring data range from sparse to not available in the study area, the DFO data were used as validation of the performance of the DFO data beginning in 1985 and is based on flood reports from news and governmental sources and therefore mainly refers to large floods in densely populated regions. It also classifies a large flood event by the significant damage to structures, agricultural land, loss to human life and/or long duration [18]. The DFO data was downloaded as a GIS shapefile set providing catalog numbers and area affected map outlines, with much of the tabular attribute data (e.g., dates, duration and fatalities) also included. It is worthy of note that DFO data are mainly based on media reports which are expected to be biased towards the more densely populated regions and/or regions of interest [18].

\subsection{Methods}

\subsubsection{GRACE-Derived Flood Potential Index}

We followed the methodology proposed by Reager and Famiglietti [17] to compute monthly 2004-2012 FPI for the study area using the GRACE TWSA product. For each grid, we defined and computed the maximum water storage capacity (Smax) and storage deficit (Sdef). Smax is the historic maximum water storage capacity of the soil within a region [17] which for our study area we estimated to be the maximum of GRACE TWSA for LNRB from 2004 to 2012. The Sdef, which represents the available water on land before obtaining Smax, was calculated for each grid and month:

$$
\operatorname{Sdef}(t)=\operatorname{Smax}-\operatorname{TWSA}(t-1)
$$

where TWSA $(t-1)$ is the saturation condition of the soil from the previous month [18]. The storage deficit shows how much more water the soil within an area can store before achieving the maximum capacity and was computed using the data from the previous month thus establishing a potential for forecasting. It is, however, expected that Sdef is low during wetter parts of the year and high during the drier part of the year. For visualization, Sdef for the study area was normalized to display the hydrological state of the basin in terms of available water.

GPCC monthly precipitation anomalies $(P)$ were multiplied by the length of each month to estimate the amount of rainfall (in $\mathrm{cm}$ ) that fell in the averaging interval:

$$
\operatorname{Pmon}(t)=P(t) d t
$$

Example of GRACE TWSC, Sdef and Pmon are shown in Figure 7 for $9.5^{\circ} \mathrm{N}, 12.5^{\circ} \mathrm{E}$. The flood potential $(F)$ for the month $(t)$ was computed by:

$$
F(t)=\operatorname{Pmon}(t)-\operatorname{Sdef}(t)
$$

where Pmon is monthly precipitation. Flood potential, $F(t)$ is the quantity of incoming water that cannot be stored based on the basin exceeding its maximum storage capacity. A high probability of flooding in the current month would mean a low storage deficit and high precipitation for the 
previous month [17]. The flood potential was further normalized to derive the Reager's flood potential index $(F P I)$ :

$$
F P I(t)=F \frac{t}{\max [F[t]]} .
$$

The values of FPI vary from $-\infty$ to 1 with positive values indicating that water input from precipitation is above the mean water storage and should be interpreted as a potential risk for flooding [17]. When normalized FPI nears 1, it indicates an abnormally high difference between precipitation and regional storage ability and therefore high flood likelihood [17]. The derived FPI was qualitatively validated against the DFO observational flood datasets.

\subsubsection{Water Budget-Derived Flood Potential Index}

The methodology in Section 2.2.1 was used in estimating the water budget FPI. The water budget Smax was estimated from the time series of the water budget TWSC. Then we calculated the water budget-based Sdef using Equation (3) and flood potential using Equation (5). For consistency, we used the GPCC precipitation in the equation for calculating the water budget flood potential. Using Equation (6), we derived the water budget-based flood potential index.

\section{Results}

\subsection{Analysis of GRACE TWSA and Validation}

We compared the three official GRACE TWSA data to each other and generated the time series for the three solutions which gave a correlation coefficient of approximately 0.99 (Figure 4) showing similar accuracy although processed using different solutions. As a result, we used the ensemble mean $[28,29]$ from the three solutions in our analysis.

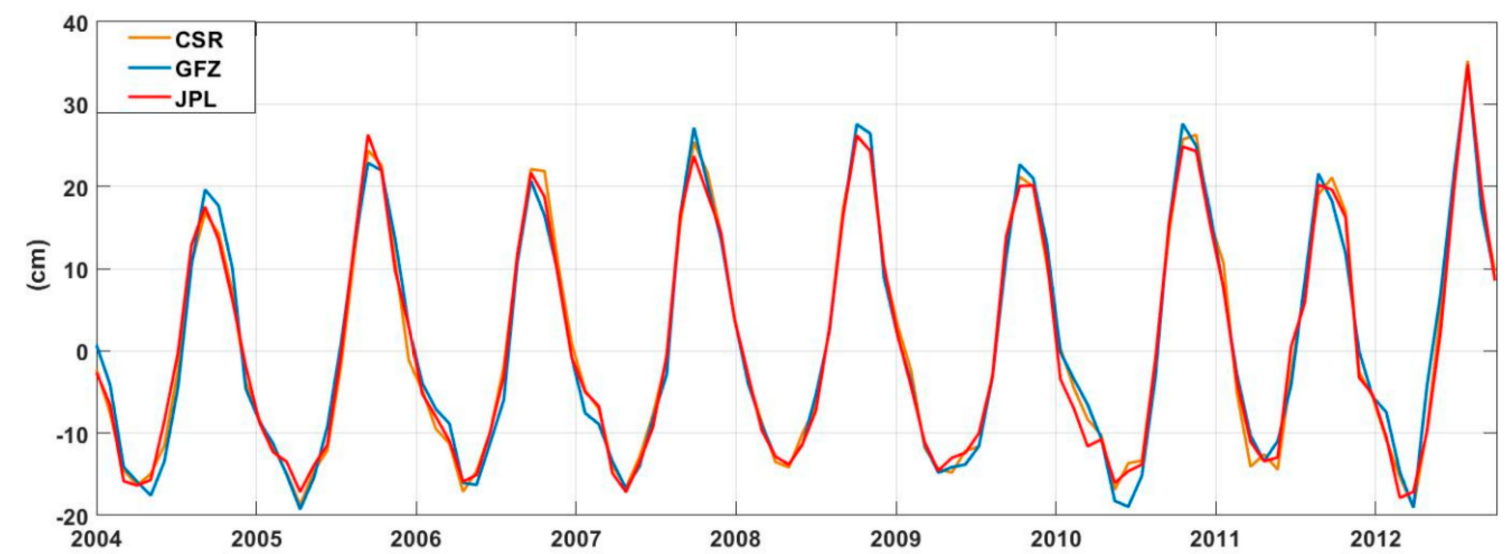

Figure 4. GRACE terrestrial water storage anomaly (TWSA) time series for the three solutions: CSR, GFZ and JPL for $9.5^{\circ} \mathrm{N}, 12.5^{\circ} \mathrm{E}$ from 2004 to 2012.

Furthermore, the time series of the GRACE-based TWSC and the derived water budget-based TWSC estimates show a considerable consistency with a correlation coefficient of 0.8 . Additionally, they both are generally negative during the dry months (November to March) and positive during the wet months (April to October). Figures 5 and 6 display the graphical relationship between GRACE TWSC and water budget TWSC in the LNRB.

\subsection{Hydrological State of the LNRB}

Figures 7 and 8 graphically explain the relationship among the variables; GRACE-based TWSC, water budget-based TWSC and their respective Sdef and Pmon. It also shows how an increasing GRACE and water budget TWSC increases with precipitation, while there is a decrease in available storage relative to the other variables. The months during which these three variables intersect implies 
a potential for flooding to occur. In the LNRB, 2005, 2007, 2008, 2009, 2010, 2011 and 2012 were flooding years $[22,30,31]$ which is consistent with Figures 7 and 8 . Figure 7 also reveals that the 2012 flood was the worst event among all.

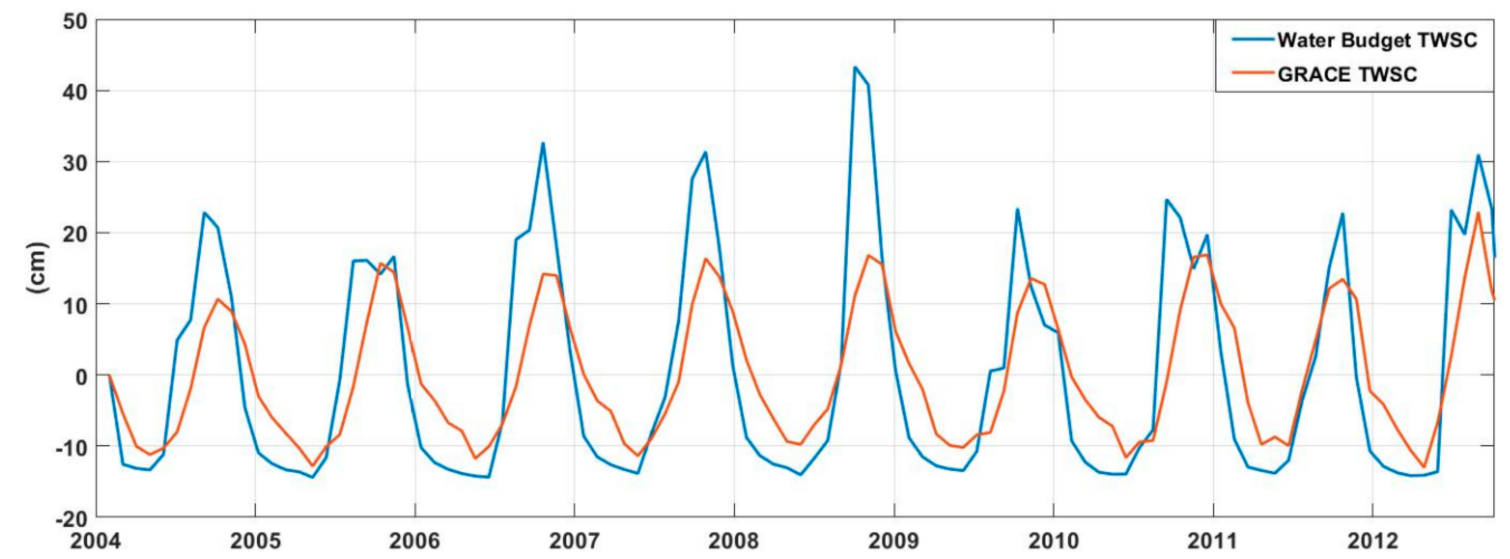

Figure 5. Comparison between GRACE terrestrial water storage capacity (TWSC) and derived water balance TWSC from 2004 to 2012 at the location of longitude 12.5 and latitude 9.5.

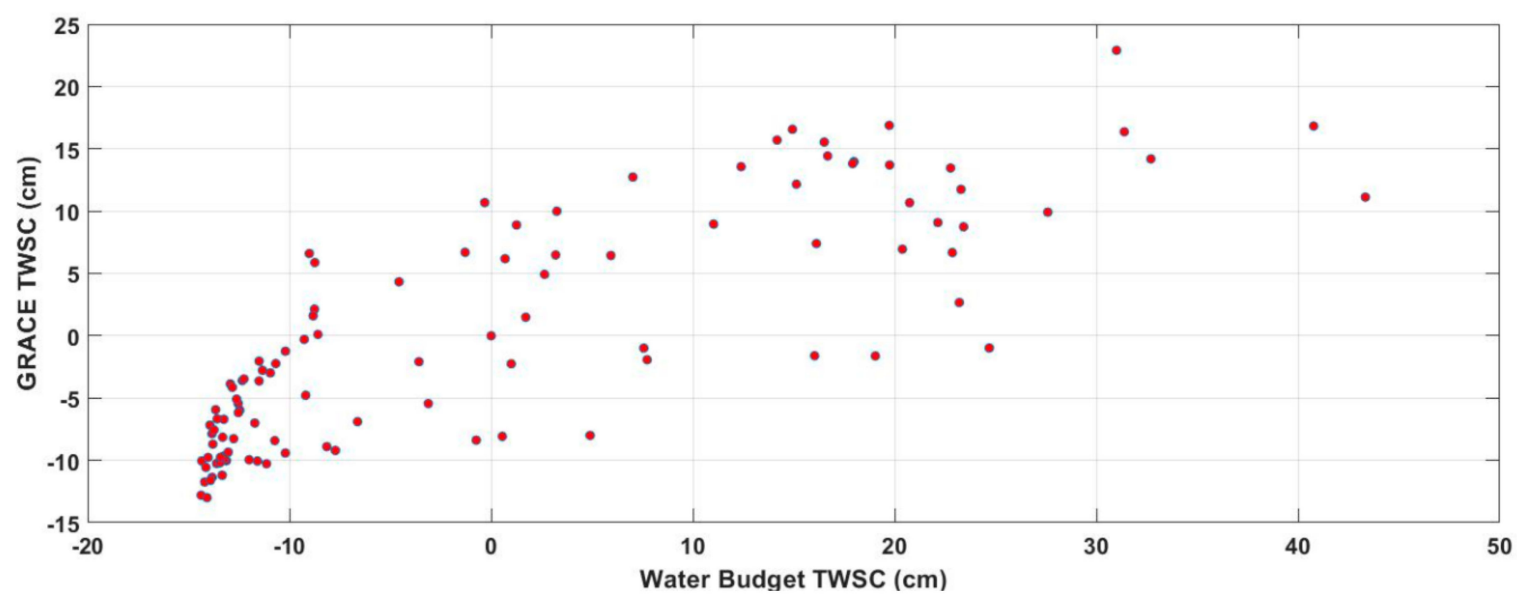

Figure 6. Scatterplot for GRACE TWSC and water budget-derived TWSC.

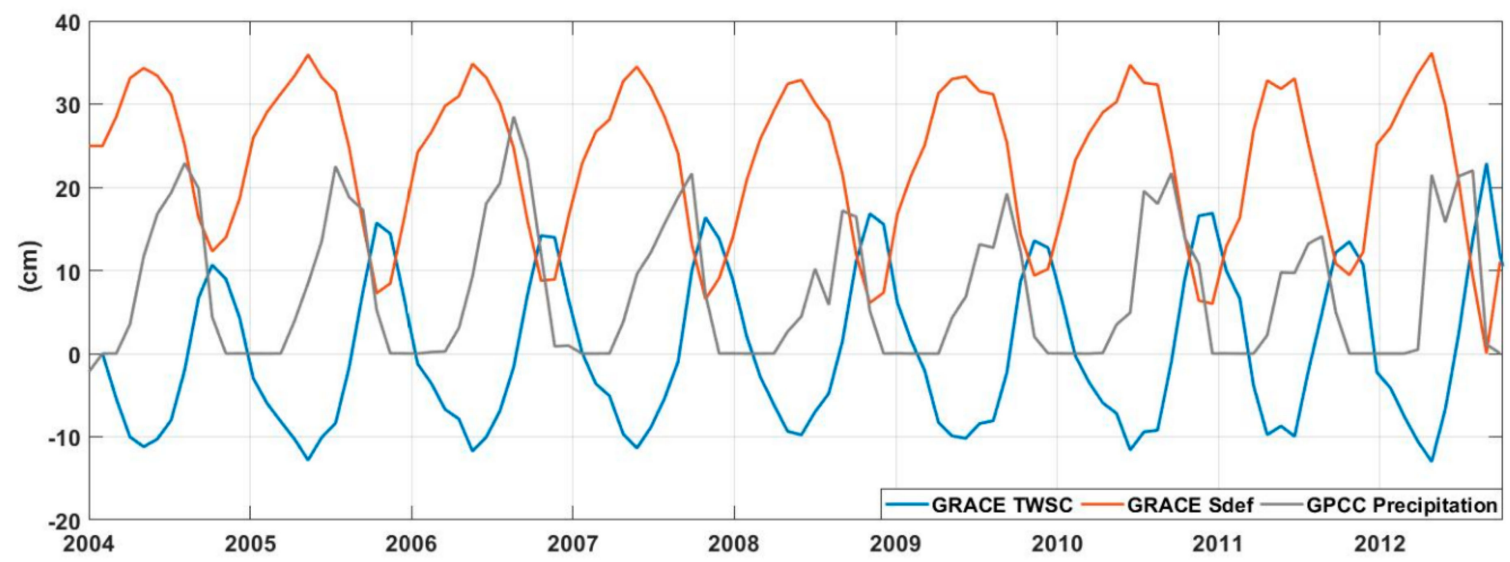

Figure 7. Variations in time series of monthly GRACE TWSC, storage deficit and precipitation for longitude 12.5 and latitude 9.5 from 2004 to 2012. 


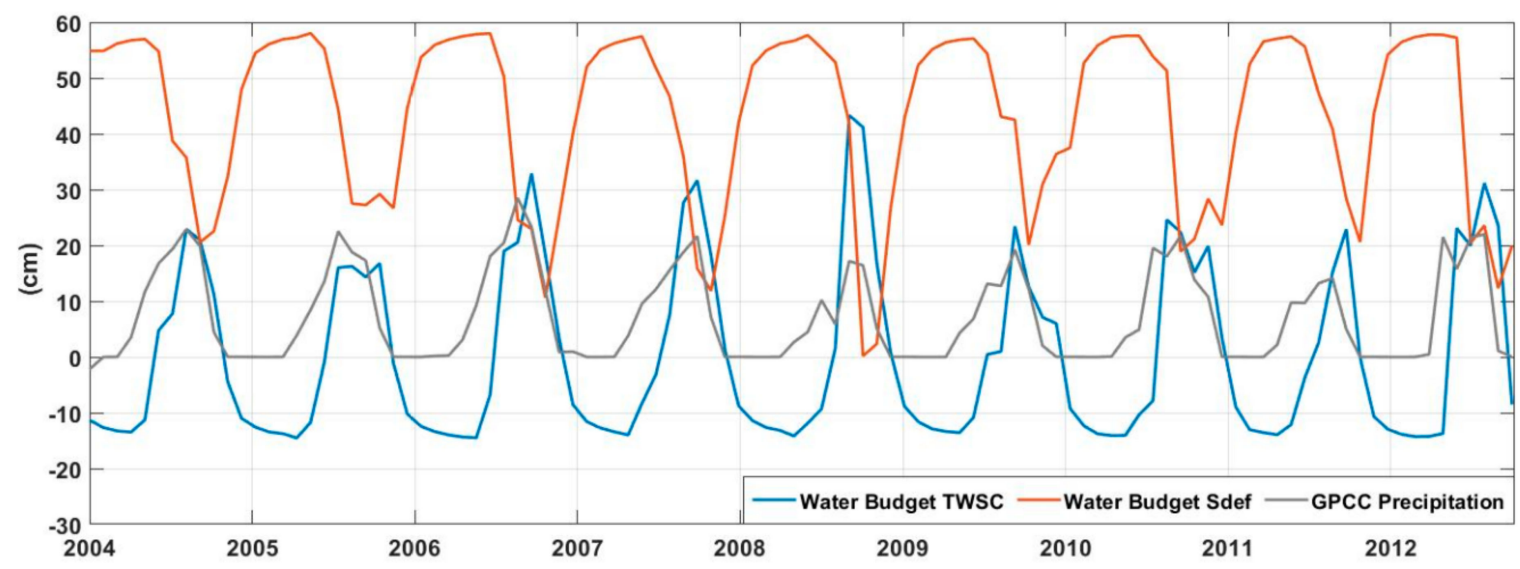

Figure 8. Variations in time series of monthly water budget TWSC, storage deficit and precipitation at the location of longitude 12.5 and latitude 9.5 from 2004 to 2012.

\subsubsection{Precipitation within the LNRB}

Rainy season varies for different geopolitical zones in Nigeria which by extension is applicable to the LNRB. The GPCC precipitation data corresponds to the wet season within the basin (Figure 8). The rainy season is between April and October. The driest months are January and December which implies 0 precipitation in both January and December. The peak month in the north is August and September in the south, which agrees well with our results as shown in Figure 9.
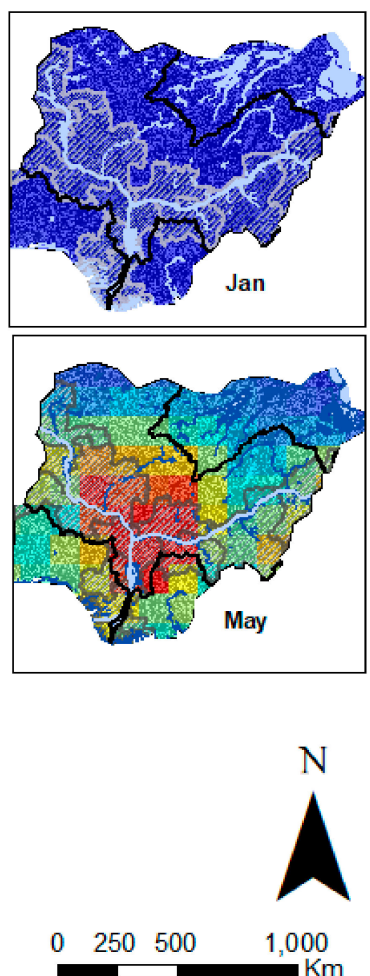
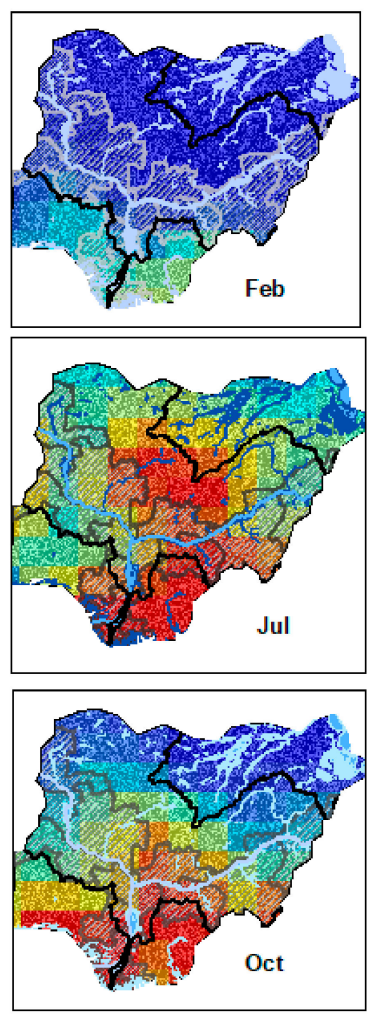
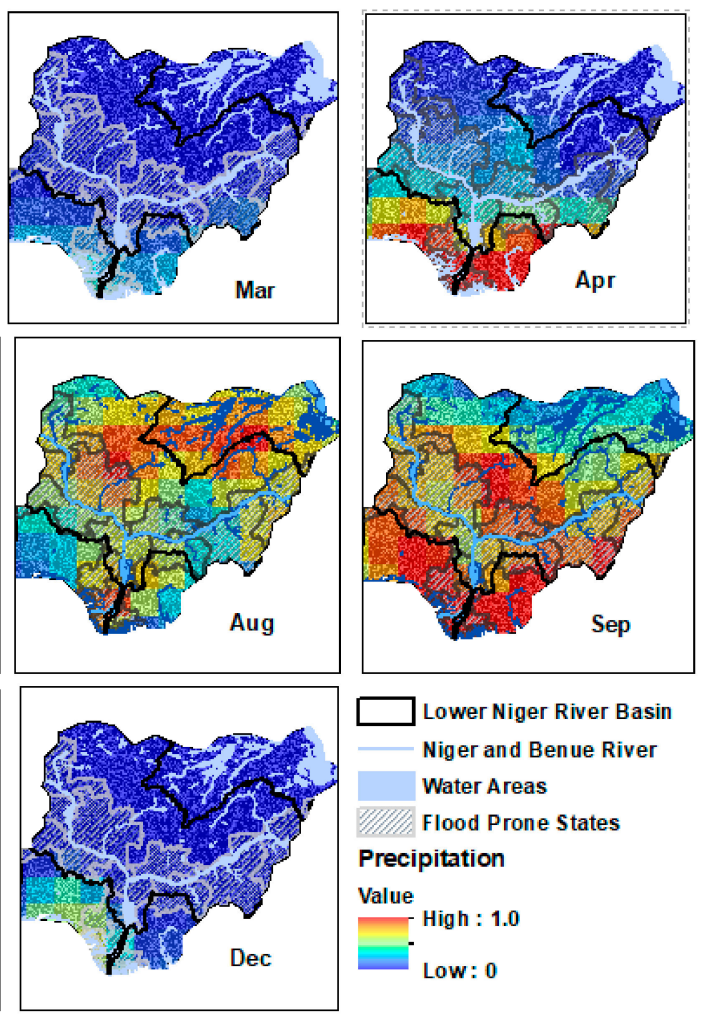

Lower Niger River Basin Niger and Benue River Water Areas

Flood Prone States Precipitation Value

High : $\mathbf{1 . 0}$

Low: 0

Figure 9. Spatiotemporal distribution of precipitation in the Lower Niger River Basin (LNRB) in 2012 from January to December. June and November were not displayed so as to show consistency when compared to GRACE data. 


\subsubsection{GRACE-Based Storage Deficit within the LNRB}

Zooming in to the 2012 flood year in the LNRB, Figure 10 visually depicts how the available storage changes from surplus to deficit; because the storage deficit was derived using GRACE TWSA from the previous month, the amount of available storage for the coming month was approximated. For example, as shown in Figure 10, available storage for the month of September 2012 was derived using the GRACE TWSA from August and the result shows a low Sdef for September 2012. With this, we estimate the amount of hydrological input necessary to cause the system to flood, hence, establishing the potential for flood prediction. Comparing Figures 9 and 10, we can infer that the available storage began to decline from the rainfall peak months, August and September.

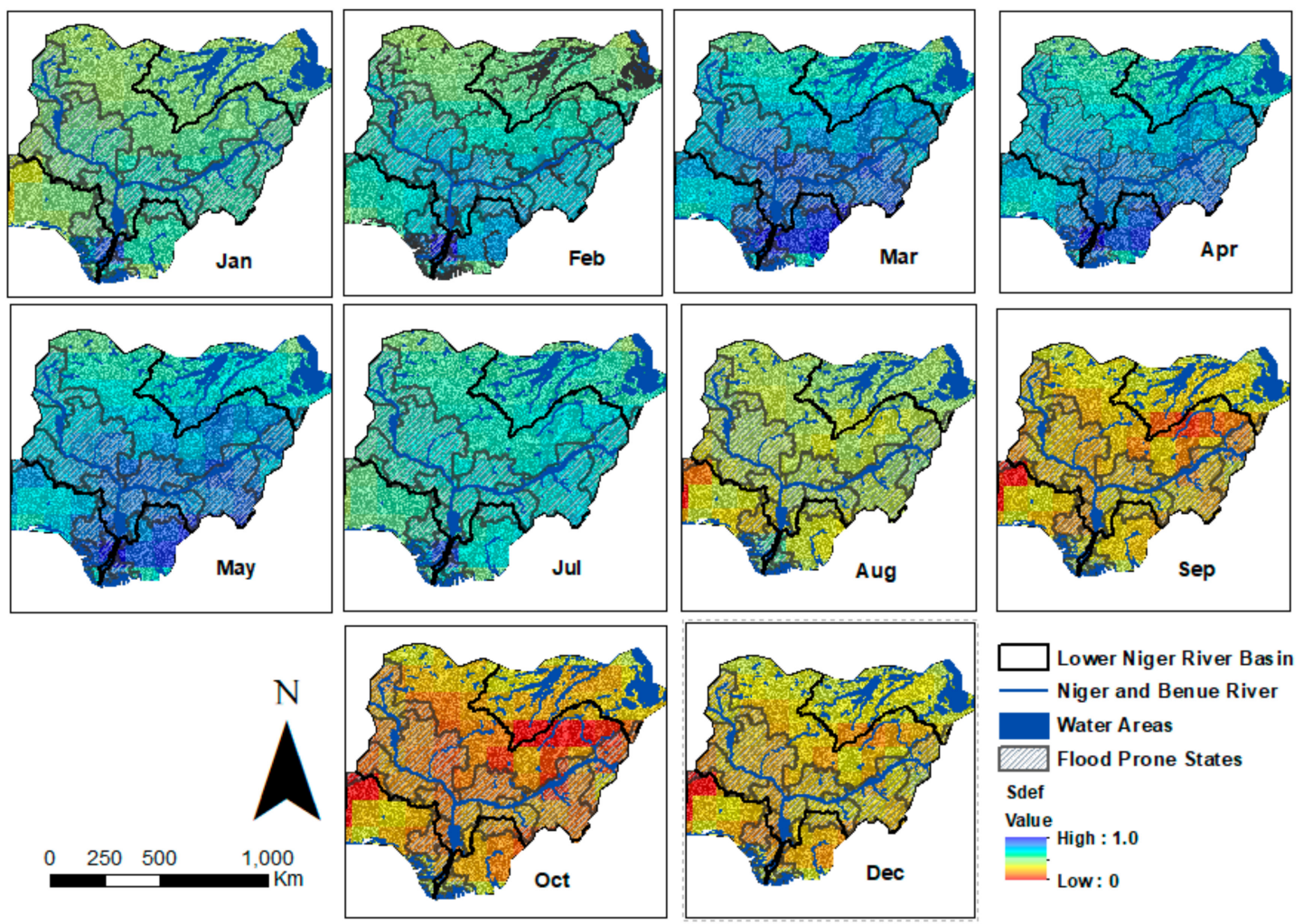

Figure 10. Spatiotemporal display of storage deficit (Sdef) (normalized) in the LNRB from January to December 2012. May and October 2012 are missing months in the GRACE TWSA time series due to battery management. Hence, no Sdef and flood potential index (FPI) for June and November. The red color shows areas with low Sdef while the blue areas represent areas with high Sdef.

\subsubsection{GRACE Flood Potential Index (FPI)}

The FPI for 2012 in the LNRB is shown in Figure 10. When compared to Figure 8, one could see how sensitive the index is to precipitation. Different areas within the basin experiences flooding at different rainfall peak times as shown in Figure 10. However, according to the Nigerian NEMA, in September 2012, 30 out of 36 states in Nigeria was affected by flooding which corresponds to the prediction by the FPI.

\subsubsection{GRACE-Based RFPI Validation}

We validated the GRACE-based FPI both quantitatively and qualitatively. The derived GRACE-based FPI was quantitatively compared to the water budget-derived FPI from 2004 to 2012 (Figure 11) and qualitatively validated against the DFO flood data for September 2005, 2007, 2009 and 2012 (Figure 11). We found a good agreement between the FPI derived from GRACE and water budget estimates as shown in Table 2, Figures 11 and 12. Figure 13 shows that both GRACE-based FPI and water 
budget-based FPI trend in the same direction. Table 2 further shows the similarities between the FPI from GRACE and water budget.

Statistical Test for GRACE and Water Budget Flood Potential Index

For statistical significance, we posed a question of whether there is a significant difference in the flood potential derived using GRACE TWSC and water budget TWSC. We used a Wilcoxon rank-sum test to test the null hypothesis that there is no difference between the FPI estimates. We also tested an alternative hypothesis, that there is a difference between the FPI estimates. Using an Alpha level of 0.05 , our result showed that we can accept the null hypothesis, and at $\mathrm{P}>0.05$, we have no reason to reject the null hypothesis that there is no difference in the flood potential estimates.

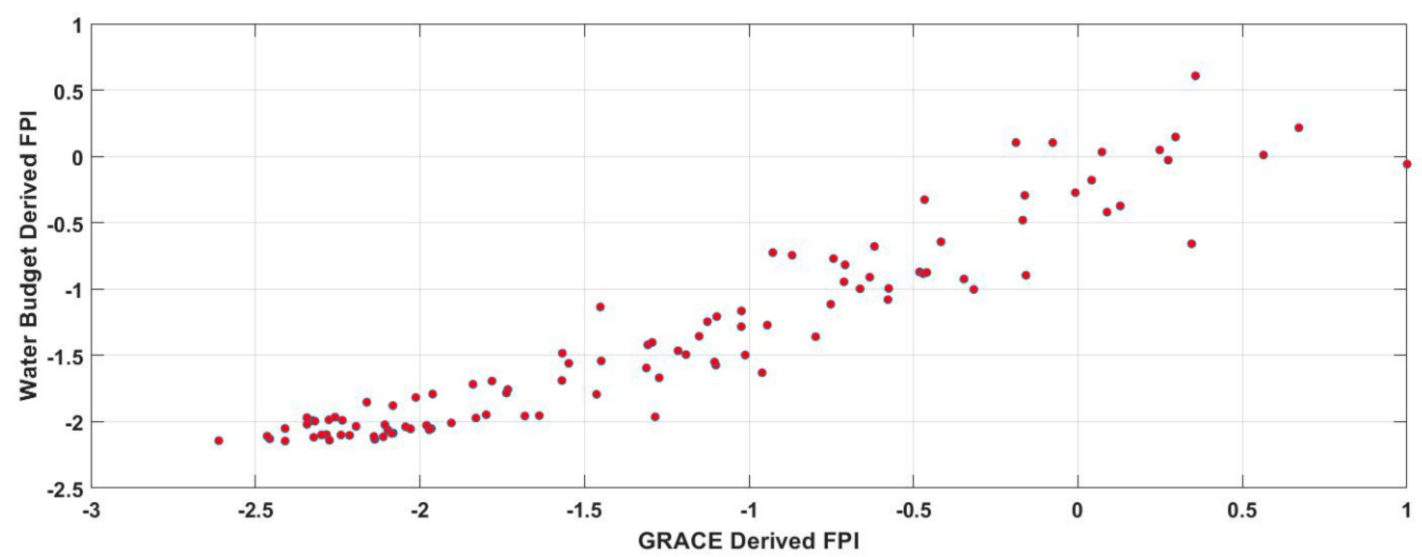

Figure 11. Scatterplot for GRACE-derived FPI and water budget-derived FPI.

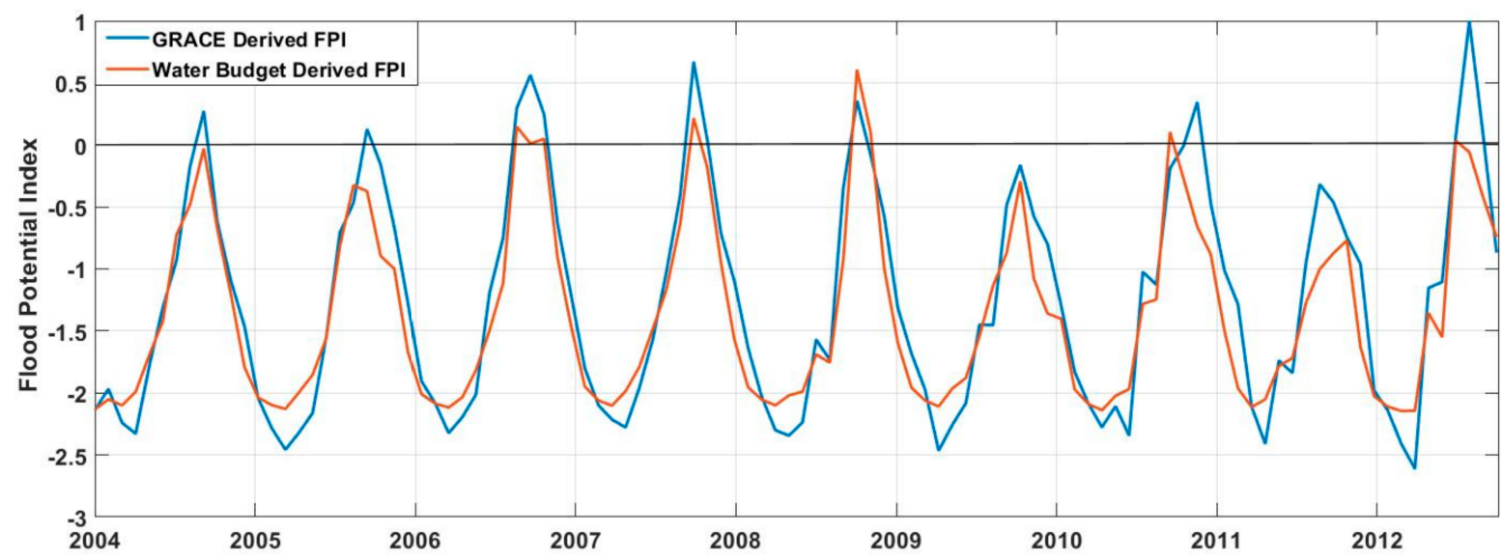

Figure 12. Graphical comparison and validation of FPI from GRACE using the FPI from water budget estimates.

Table 2. Tabular representation of the comparison between FPI from GRACE and water budget estimates.

\begin{tabular}{ccc}
\hline Years & \multicolumn{2}{c}{ Flood Potential Index } \\
\hline September & GRACE-Based FPI & Water Budget-Based FPI \\
\hline 2005 & 0.2 & -0.3 \\
2006 & 0.6 & 0.2 \\
2007 & 0.7 & 0.3 \\
2009 & -0.3 & -0.2 \\
2010 & 0.4 & 0.2 \\
2012 & 0.9 & 0.1 \\
\hline
\end{tabular}




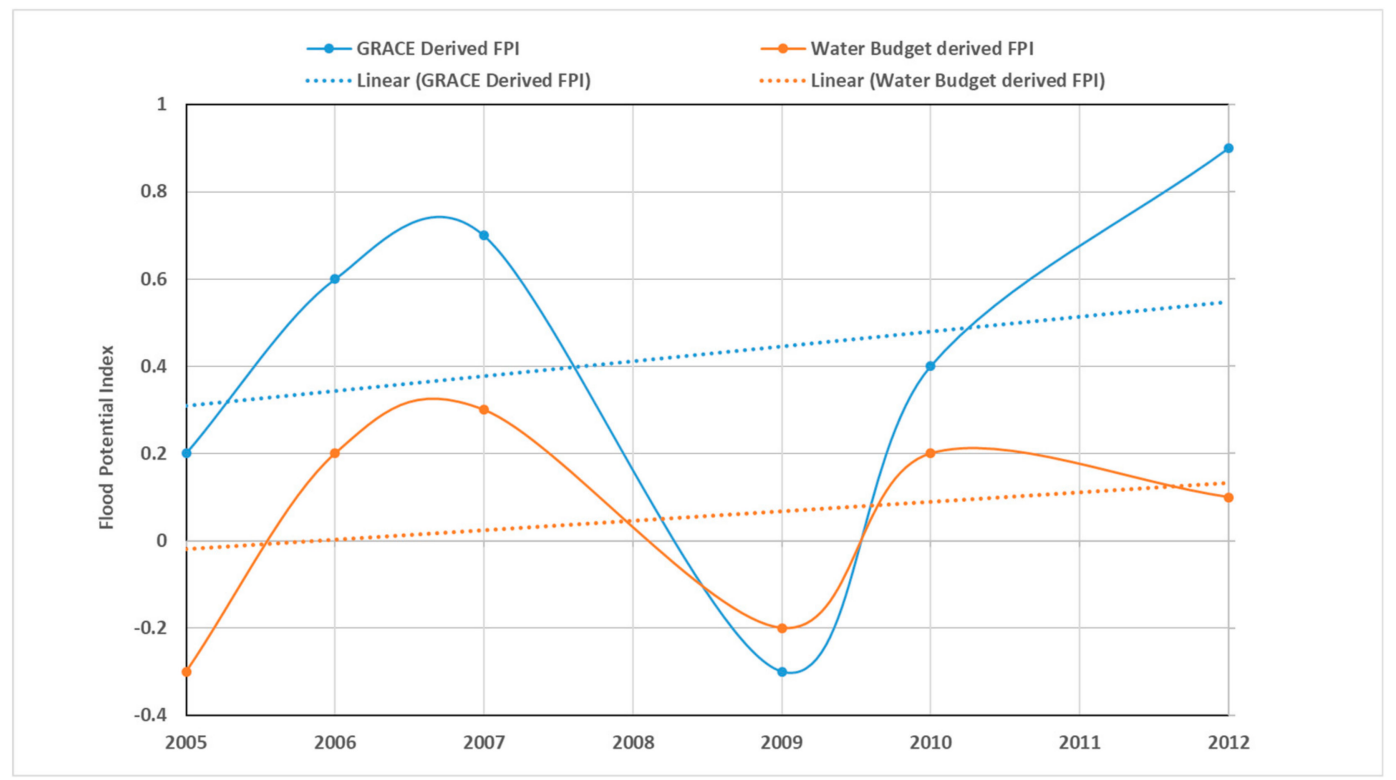

Figure 13. Trend plots for GRACE-derived and water budget-derived FPIs.

We chose big flood events that got publicity within our period of study so as to see how well the GRACE-based FPI compares to the DFO reported floods. However, because the DFO flood report is based on news, it is more biased towards urban flood events. These flood events reported in our study area in September 2005, 2007, 2009 and 2012 were also predicted by the GRACE-based FPI (Figure 14). Also, the FPI values from GRACE (Table 3) predicted flooding for the flood-prone/worst-hit state in September 2012 as reported by the Nigerian NEMA.
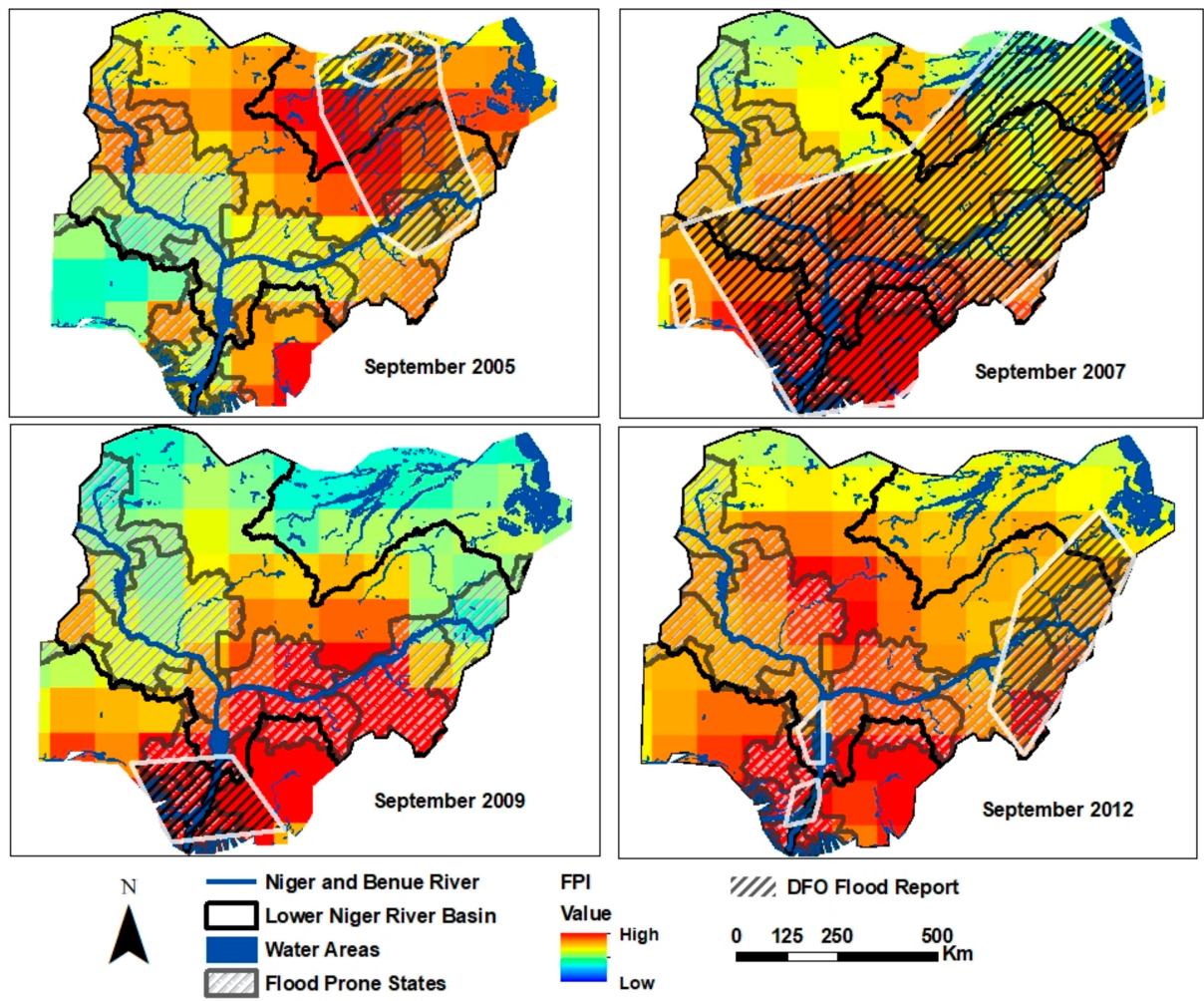

"II//. DFO Flood Report

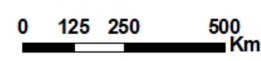

Figure 14. Comparison between GRACE-based FPI predicted floods and DFO reported floods. 
Table 3. GRACE-based FPI values for the flood-prone/worst-hit states in September 2012.

\begin{tabular}{ccc}
\hline Year & Flood Prone States & FPI \\
\hline & Adamawa & 1 \\
& Anambra & 0.5 \\
& Bayelsa & 0.4 \\
& Benue & 0.8 \\
& Delta & 0.5 \\
고 & Edo & 0.4 \\
& Kebbi & 0.5 \\
& Kogi & 0.7 \\
& Kwara & 0.5 \\
& Nassarawa & 0.4 \\
& Niger & 0.8 \\
& Rivers & 0.7 \\
& Taraba & 0.6 \\
\hline
\end{tabular}

\section{Discussion}

Reager and Famiglietti [17] demonstrated that GRACE TWSA data can reveal when river basins have been filling with water over several months, when it rains, and the basin becomes full, and floods. The available storage or Sdef for LNRB (Figure 10) began to decrease August to October 2012 which represents the peak rainy season in the study area. Further, since soil moisture is critical in the accurate prediction of floods and general runoff [17], the storage deficit serves as an indicator in flood studies. The correlation coefficients of -0.7 for storage deficit and precipitation shows the inverse relationship that exists between the two variables which further supports the conclusion made by Reager and Famiglietti [17] that the storage deficit can be used with traditional methods of precipitation forecasting to determine the likelihood for flooding during the coming weeks. We also analyzed the relationship between storage deficit and FPI and found that storage decrease with an increase in the potential for flooding had a correlation coefficient of -0.8 .

The FPI seems to perform well where flooding is mainly caused by heavy rainfall events [18] which was the case in Nigeria and by extension, LNRB. Heavy rainfall that occurred in August and September 2012 caused the major rivers, especially the Benue River, to overflow its banks, which led to authorities releasing water from the dams located within the basin (Cameroon). For our analysis, the FPI captured and predicted the flood events in LNRB in 2012 (Figures 12 and 15) which was also reported by the Nigerian NEMA and DFO (Figure 14) [30,31]. For validation of the GRACE-based FPI using the water budget-derived FPI, we tested the hypothesis that there is no difference between the indices using the alpha value of 0.05 . With a correlation coefficient of 0.9 and $\mathrm{P}>0.05$ we have no reason to reject the null hypothesis.

The GRACE-based FPI and storage deficit, though invaluable, have limitations. The coarse spatial $\left(>200 \mathrm{~km}^{2}\right)$ and temporal (monthly) resolutions of the GRACE data also makes it limited and unsuitable for forecasting local scale and flash floods $[15,18]$, which may, therefore, make the FPI less effective. It has, however, an unequaled capability to monitor available water storage when combined with precipitation forecasting data and could increase warning lead time from one month to two months [17].

However, the relationship between the GRACE and water budget-based FPI shows promise when finer spatial and temporal resolutions data are used in deriving water budget TWSC (Equation (1)), thus making it a supplement to the GRACE-based FPI and possibly reducing the limitation of the GRACE TWSA. 


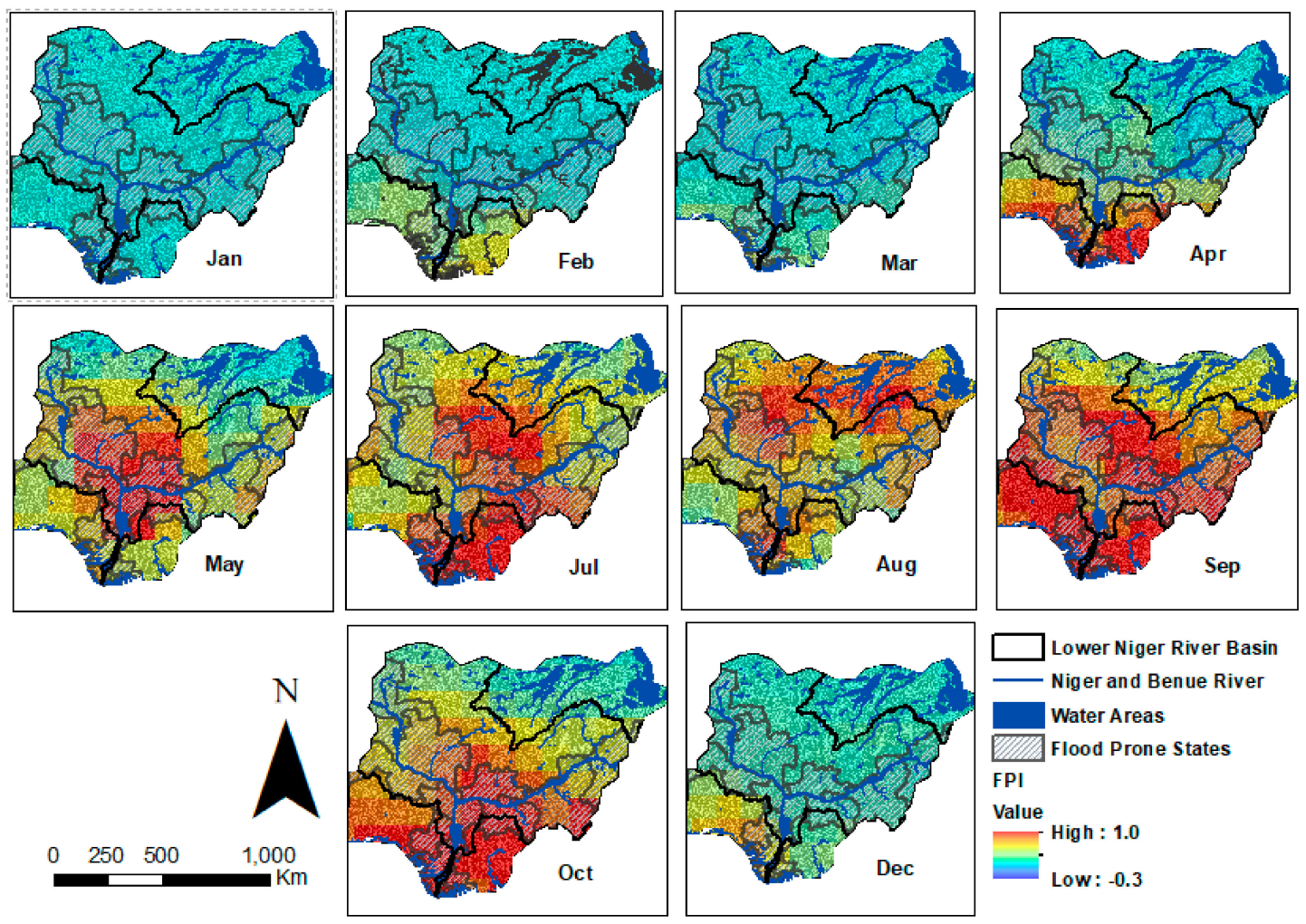

Figure 15. Spatiotemporal distribution of the flood potential index for 2012 in the LNRB. The red and blue areas indicate high and low probability or likelihood of flooding. According to the Nigerian National Emergency Management Agency (NEMA), 30 out of 36 states experienced flooding.

\section{Conclusions}

We estimated the hydrological conditions of the study area in terms of available storage and precipitation prior to the 2012 catastrophic flood using GRACE TWSA and GPCC data respectively. We also validated the GRACE TWSC using the water budget estimates TWSC, calculated the GRACE-based FPI for the basin, quantitatively and qualitatively compared the result to the water budget-based FPI and DFO flood report respectively. Based on our findings, we can make the following conclusions.

The GRACE TWSA and the derived FPI are both sensitive to precipitation by showing peaks and troughs in their time series which corresponds to wet season (peak) and dry season (trough). Based on the hydrological conditions of the study area in terms of precipitation and antecedent water storage state prior to flooding, the basin had a high amount of rainfall in August 2012 and could not balance the amount of incoming precipitation for September 2012 which then led to flooding.

The GRACE TWSA limitations could be managed assuming the GRACE-based FPI is supplemented with the water budget-derived FPI and using the water budget TWSC calculated from lower spatial and temporal data.

Therefore, the GRACE-based TWSA, Sdef and FPI in combination with other precipitation forecasting data and water budget-based TWSC/FPI could be utilized for operational flood monitoring in developing countries like Nigeria, where the unavailability of technical manpower, security and the cost of implementing and installing sophisticated flood monitoring/predicting measures could be prohibitive. In terms of cost, most satellite data are relatively cheap and readily available. Additionally, the current issue of security in some of the northern parts of the country prone to flooding might hinder the installation of flood monitoring devices, thus making remote-sensing products a viable option and an invaluable resource in flood studies in regions with little or no flood monitoring data. 
Author Contributions: Conceptualization, D.I. and W.Z.; methodology, D.I. and W.Z.; validation, D.I.; formal analysis, D.I.; data curation, D.I.; writing-original draft preparation, D.I.; writing-review and editing, W.Z.; visualization, D.I.; supervision, W.Z.; project administration, W.Z.; funding acquisition, W.Z. and D.I.

Funding: This work was funded by the American Association of University Women (AAUW) scholarship in 2018, and the Chevron international fellowship at the Colorado School of Mines in 2019.

Acknowledgments: We acknowledge the use of data products or imagery from the Land, Atmosphere Near real-time Capability for EOS (LANCE) system operated by NASA's Earth Science Data and Information System (ESDIS) with funding provided by NASA Headquarters. Special thanks to Stephen Semmens, Ashton Krajnovich and Kendall Wnuk for offering their constructive feedback.

Conflicts of Interest: The authors declare no conflict of interest.

\section{References}

1. Folorunsho, R.; Awosika, L.F. Flood Mitigation in Lagos, Nigeria through Wise Management of Solid Waste: A Case of Ikoyi and Victoria Islands, Nigeria. Paper Presented at the UNESCO-CSI Workshop Maputo, Maputo, Mozambique, 19-23 November 2001.

2. Olajuyigbe, A.; Rotowa, O.; Durojaye, E. An assessment of flood hazard in Nigeria: The case of mile 12, Lagos. Mediterr. J. Soc. Sci. 2012, 3, 367-375.

3. Bartholmes, J.C.; Thielen, J.; Ramos, M.H.; Gentilini, S. The European flood alert system EFAS - Part 2: Statistical skill assessment of probabilistic and deterministic operational forecasts. Hydrol. Earth Syst. Sci. 2009, 13, 141-153. [CrossRef]

4. Scawthorn, C. Modeling flood events in the US. In Proceedings of the Euro Conference on Global Change and Catastrophe Risk Management, HASA, Laxenburg, Austria, 6-9 June 1999.

5. Tariq, M.A.U.R. Risk-Based Planning and Optimization of Flood Management Measures in Developing Countries: Case Pakistan. Ph.D. Thesis, VSSD, Delft University of Technology, Delft, The Netherlands, 2012.

6. Victor, K. Remote Sensing of Floods and Flood-Prone Areas: An Overview. J. Coast. Res. 2015, 31, $1005-1013$.

7. Nasreddine, B.; Feng, Z.; Luca, B.; Yanbo, H.; Yumin, T. Near-Real-Time Flood Forecasting Based on Satellite Precipitation Products. Remote Sens. 2019, 11, 252. [CrossRef]

8. Sheffield, J.E.F.; Wood, N.; Chaney, K.; Guan, S.; Sadri, X.; Yuan, L.; Olang, A.; Amani, A.; Ali, S.; Demuth, L. A Drought Monitoring and Forecasting System for Sub-Sahara African Water Resources and Food Security. Bull. Amer. Meteor. Soc. 2014, 95, 861-882. [CrossRef]

9. Zhang, X.; Tang, Q.; Liu, X.; Leng, G.; Li, Z. Soil Moisture Drought Monitoring and Forecasting Using Satellite and Climate Model Data over Southwestern China. J. Hydrometeor. 2017, 18, 23. [CrossRef]

10. Hossain, F.; Anagnostou, E.N. Assessment of current passive-microwave- and infrared-based satellite rainfall remote sensing for flood prediction. J. Geophys. Res. Atmos. 2005, 110, D07102. [CrossRef]

11. Brakenridge, R.; Anderson, E. Modis-Based Flood Detection, Mapping and Measurement: The Potential for Operational Hydrological Applications. In Transboundary Floods: Reducing Risks Through Flood Management; Marsalek, J., Stancalie, G., Balint, G., Eds.; Nato Science Series IV: Earth and Environmental Sciences; Springer: Dordrecht, The Netherlands, 2006; pp. 1-12.

12. Zhan, X.; Ryu, D.; Crow, W. Improving Flood Prediction Through the Assimilation of AMSR-E Soil Moisture Retrievals into a Hydrologic Model; American Geophysical Union, Fall Meeting Moscone Center: San Francisco, CA, USA, 2006; abstract ID: H23E-1545.

13. Adam, D. Gravity measurement: Amazing GRACE. Nature 2002, 416, 10-11. [CrossRef] [PubMed]

14. Chen, J.L.; Wilson, C.R.; Tapley, B.D.; Ries, J.C. Low degree gravitational changes from GRACE: Validation and interpretation. Geophys. Res. Lett. 2004, 31, L22607. [CrossRef]

15. Longuevergne, L.; Scanlon, B.R.; Wilson, C.R. GRACE Hydrological estimates for small basins: Evaluating processing approaches on the High Plains Aquifer, USA. Water Resour. Res. 2010, 46, W11517. [CrossRef]

16. Reager, J.T.; Thomas, B.F.; Famiglietti, J.S. River basin flood potential inferred using GRACE gravity observations at several months lead-time. Nat. Geosci. 2014, 7, 588-592. [CrossRef]

17. Reager, J.T.; Famiglietti, J.S. Global terrestrial water storage capacity and flood potential using GRACE. Geophys. Res. Lett. 2009, 36, L23402. [CrossRef]

18. Molodtsova, T.; Molodtsov, S.; Kirilenko, A.; Zhang, X.; VanLooy, J. Evaluating flood potential with GRACE in the United States. Nat. Hazards Earth Syst. Sci. 2016, 16, 1011-1018. [CrossRef] 
19. Sun, Z.; Zhu, X.; Pan, Y.; Zhang, J. Assessing Terrestrial Water Storage and Flood Potential Using GRACE Data in the Yangtze River Basin, China. Remote Sens. 2017, 9, 1011. [CrossRef]

20. IFRCS - International Federation of Red Cross and Red Crescent Emergency Appeal; Nigeria: Floods. Available online: http://reliefweb.int/sites/reliefweb.int/files/resources/MDRNG01401.pdf (accessed on 10 January 2019).

21. Kwari, J.W.; Paul, M.K.; Shekarau, L.B. The Impacts of Flooding on Socio-Economic Development and Agriculture in Northern Nigeria: A Case Study of 2012 Flooding in Yola and Numan Areas of Adamawa State Nigeria. Int. J. Sci. Eng. Res. 2015, 6, 1433-1442.

22. Mazawaje, D.F.; Tsenbeya, I.T.; Ismaila, A.B. Analysis of the determinants of floods in Numan Town, Nigeria. J. Environ. Sci. Eng. 2014, B3, 264-273. [CrossRef]

23. NASA Earth Observatory-Flooding in Nigeria. Available online: https://earthobservatory.nasa.gov/images/ 79404/flooding-in-nigeria (accessed on 20 August 2019).

24. Swenson, S.C. GRACE Monthly Land Water Mass Grids NETCDF RELEASE 5.0 Ver. 5.0. PO. DAAC, CA, USA, 2012. Available online: http://dx.doi.org/10.5067/TELND-NC005 (accessed on 20 September 2018).

25. Velicogna, I.; Wahr, J. Measurements of time-variable gravity show mass loss in Antarctica. Science 2016, 311, 1754-1756. [CrossRef] [PubMed]

26. EartH2Observe project, Plymouth Marine Laboratory Remote Sensing Group, European Union's Seventh Programme for Research, Technological Development and Demonstration under Grant Agreement No. 603608. Available online: https://wci.earth2observe.eu/ (accessed on 10 October 2018).

27. Schneider, U.; Becker, A.; Finger, P.; Meyer-Christoffer, A.; Rudolf, B.; Ziese, M. GPCC Full Data Reanalysis Version 6.0 at $1.0^{\circ}$ Monthly Land-Surface Precipitation from Rain-Gauges built on GTS-based and Historic Data 2011. Available online: https://opendata.dwd.de/climate_environment/GPCC/html/fulldata_v6_doi_ download.html (accessed on 23 September 2018). [CrossRef]

28. Sakumura, C.; Bettadpur, S.; Bruinsma, S. Ensemble prediction and intercomparison analysis of GRACE time-variable gravity field models. Geophys. Res. Lett. 2014, 41, 1389-1397. [CrossRef]

29. NASA-JPL. GRACE D-103133 Gravity Recovery and Climate Experiment Level-3 Data Product User Handbook; NASA-JPL: Pasadena, CA, USA, 2019.

30. DFO (Dartmouth Flood Observatory), Global Active Archive of Large Flood Events. Available online: http://www.dartmouth.edu/ \{\}floods/Archives/ (accessed on 14 December 2018).

31. Climate-Data.Org. Climate Adamawa. Available online: https://en.climate-data.org/africa/niger/zinder/ adamawa-349376/ (accessed on 22 February 2019). 